Lawrence Berkeley Laboratory

University of California

Berkeley, California 94720
LBL-POB--496-No. 3

DE87 000947

PUB -496

No. 3

October 1986

\title{
Bevalac Operations Update
}

This is the third in a series of reports on Bevalac operations. Your comments and input of information are welconed - G.F. Krebs.

\section{A. Bevatron Operations}

It is now time to report on the aggregate program accomplished for FY 1986, a year of austerity forced upon us by the Gram-Rudman deficit reduction 1aw, effective last January. Our full progran ended at the end of April, and an abbreviated program, using neon from the local injector at energies less than $1 \mathrm{GeV} / \mathrm{n}$, was carried out during may. for the year we were able to provide a total of 3011 research hours, 2044 for nuclear science and 968 for the biomedical program. In the nuclear science discipline, thirteen major experimerits were run, and thirteen other experiments either were run or were able to perform equipment and feasibility tests.

Major runs include the following:

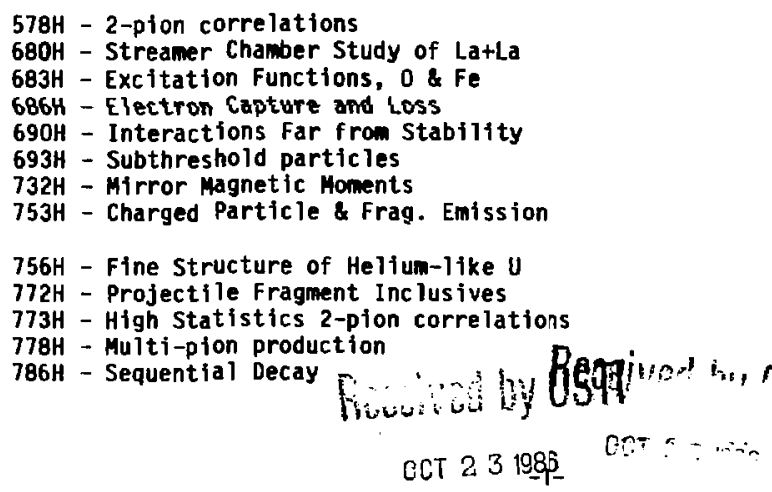

LBL \& Zurich

MSU

LSU \& LBL.

LB'

Tokyo, Osaka, et al UCLA, LBL, UC Davis Osaka, Tokyo, LBL Los Alamos, 8NL, Dak Ridge, Heizmarn

L8L

L8L, INS, UCSSL GSI, LBL

UCR

$778 \mathrm{H}$ - Multi-pion production Th. THaryland, LBL 
Operating plans for this coming year are not yet completely determined, because of remaining uncertainties in the FY 1987 budget. We will be starting with normal operations in the first quarter, and will publish a schedule as soon as the budget question is resolved, probably by mid fall.

Great emphasis will be placed during this running year on improving the effectiveness of the Fast Switch mode of operation. We have made several significant improvements in hardware and software during this sumer shutdown which will make this mode easier to carry out. He expect to see a big improvement in operational efficiency, and hopefully a higher fraction of data-taking hours.

\section{User Communications}

We proudly announce that a user comunications mailbox is now on-line at LQL. At the suggestion of the Technical Adyisory Comittee of the Users' Association, and with the acquisition of sufficient computer terminal power in the Bevalac offices, we have established a subdirectory containing infomation for the users and electronic mail facilities for conmunications with the Bevalac through the ARC office.

Our address is CSA::BEYOPS on DECnet. We will be maintaining information in [BEVOPS.BILLBOARD] on active experiments, ions available, long term scheduling, notes of general interest, etc. Your input is Invited as to the subjects we should post. Commications via electronic mail may be directed to Jose Alonso, Gary Krebs, fred Lothrop, the ARC Office staff, or others known to be at the Bevalac, either the siaff here or visiting users, through the CSA: :BEVOPS mail drop. (F. Lothrop) 


\section{B. User Support at the Bevalac}

Improving user support remains one of the principal goals of the Operations Group at the Bevalac. We feel that significant strices have been made in the past year, with the implementation of "Hotel Bevalac" and with the instrument pool managed by Gary Krebs, but always acknowledge that more is possible.

I am happy to report that "more" will in fact be possible this year, in the form of two additional physicists to provide support for users, primarily in the low energy and atomic physics programs. Dick McDonald, known to many of you as the dynamic and highly successful liaison officer at the SuperHILAC, has agreed to spend a significant portion of his time providing physics support for the above-mentioned programs at the Bevalac. Peggy McMahon has just joined our staff, coming from active research with the Moretto Group in the Nuclear Science Diyision. She will be spending at least half of her time working with Dick HcDonald in his user support activities at the SuperHILAC and the Bevalac. With her strong experimental background, and her excellent knowledge of data acquisition software she will be a very valuable asset to our experimental programs.

What I find most exciting about these recent developinents is that now most beam lines and experimental facilities have a physicist dedicated to the direct support of their research programs. Howard Wieman manages the B42 HISS facility; Bill Chu, with able assistance from $\mathrm{Iim}$ Renner and Bernhardt Ludewigt run the radiobiology and radictheapy programs; Hank Crawford manages the $B 40$ area and the NASA program; Dick and Peggy handle the 839, low energy portions of the 844 progran;, nuclear chemistry irradiations, and the atomic physics activities in 840; while Gary Krebs looks after the Streamer Chamber, 830 area, and the Kaon program in B44. 
In addition, Gary carries primary responsibility for the EPB area, beam line conditions and tunes, and overall user relations.

This tean, coupled with the technical support available from the mechanical and electronics crews should provide a better level of user support than has been available before, and should contribute to inuch greater productivity for our research program. (J. Alonso)

\section{General}

In a move to save power some ten EPB quadrupoles have had new pole tips installed reducing their gap from $12 \mathrm{in.}$ to 8 in. The gradients of the new quadrupoles were measured by the Magnetic Measurements Group $(D$. Nelson, et al), and graphs of gradient vs. current for the new quadrupoles will be in an updated Bevalac Users Handbook. The updated handbook, subject to review by the Technical Advisory Comittee in Sept. 1986, should go to press in Oct. 1986.

A Optics Handbook has been written and will become avallable in the fall of '86. This handbook will be used by the Main Control Room and will be available to experimenters. Each beam line is described and 'standard' tunes shown. The handbook contains all magnet and drift space parameters such that a Transport TLIST can easily be examined. 8ELIN (a Transport type computer program) is now in the BEY Vax and available to all experimenters. Instructions on how to use this program are now being written.

At the end of beam 30 there are two storage areas. We are in the process of turning these areas into experiment staging areas. There hns been a need for such areas for a long time. Carpentry work and air conditioning work is in progress. 
A major overhauling of the plunging magnet system was carried out during this past shutdown period. As well, new beam profile monitors were installed in the transfer line. This improved monitoring will result in a more efficient tuning of the transfer line.

A new beam spill control has been developed in an effort to reduce the structure of the Bevalac beams. This system will use an improved feedback loop starting with the signal from the Fl scintillator. The installation and commissioning of this system will occur in the upcoming running period.

Additions have been made to the basic MOD COMP computer system at the Bevalac. Purchased were one SUN $3 / 160$ M workstation (4 H bytes, 130 H byte disk, $60 \mathrm{M}$ byte cassette type) and two SUN $3 / 50$ (4 M byte) diskless vorkstations. Associated with the workstations are 79 inch monitors (1782 $\times 900$ monochrome). The $3 / 50$ stations are connected to the $3 / 160$ via ethernet. These stations will be used initially for the monitoring of power consumption by the external particle beam line magnets. The SUN system will be evaluated for use in a major upgrading of the Bevalac control systems, planned for FY 1988.

\section{Local Injector}

Modifications to the RF system of the local injector were completed during the summer shutdown period. This work had as its major goal the simplification of local injector operations. Modifications were made to the modulator and power amplifiers. Previously, the two Alvarez linac tanks shared a common driver amplifier requiring high power splitters and phase shifters which were difficult to tune. As a result of the RF improvements each Alvarez tank now has its own dedicated drive chain with 
independent low-level adjustment of amplitude and phase, allowing for easier tuning for different ions. The local injector will resume operation in october and provide the Bevalac with a source of light 5 MeV/n ions. (R. Gough)

\section{E. Beam Lines}

\section{Beam*26}

During the initial resurveying of $B 26$ in 1985 a number of magnets were realigned (see Bevalac Operation's Update Mo. 2). In addition it was discovered that more surveying was required to properly align the prep. box at focal point 3 and wire chamber No. 2. This work was completed in August ' 86 . We expect the tine for tuning of this bean line to be further reduced. Some difficulty was experienced triggering the streamer chamber with low-energy incident beams when the streamer chamber magnet was running at its maximum. It was suggested that a repositioning of the trigger scintillators may solve the problem. The beam 26 quadrupoles Q2A, Q2B (previously 12 in. gap) were rebuilt with new pole tips and now have an $B$ in. gap. Extensive studies had been undertaken to determine that an $\theta$ inch gap is in fact totally adequate for transporting all the beams used by the streamer chanber.

\section{Beam 30}

The shielding upstream of the di-lepton spectrometer system (0LS) was removed. The quadrupoles 83001,83002 which previously had a 12 in. gap were a1so changed to an 8 in. gap. The magnet and shielding work was completed in September ' 86 . One of the DLS magnets was refitted with new coils and was returned to the 830 cave in September. The full DLS system (magnets, drift chambers, Cerenkov detectors and nodoscopes) will be in place before the end of September ' 86 . The $B 30$ shack and computer room 
have had a sprinkler system installed. Problems with the air conditioning - system have arisen and a solution is now under review. We will make revisions and have the system operating again before the first B30 run.

\section{Beam 39 (LEBL)}

The low energy beam line was last run in December ' 85 for the LANL, ORNL, BNL, Weizmann Inst. collaboration, experiment $753 \mathrm{H}$. Their detection apparatus is still in place in the 839 cave. Four 83912 in. gap quadrupoles will be changed to 8 in. gap quadrupoles: B39Q1A, $B$ and B39Q2A,B. Installation should occur in the fall of ' 86 .

\section{Beam 40}

Modifications to the $Y$ vacuum tank downstream of B40M3 are being drawn up. A removable plate will be installed on the top of the tank such that four scintillators locating up-down. left-right may be moved in and out of the beam line for accurately defining beam position. For atomic physics experiments, movable slits are being installed near B40Q1B and B40Q2A for production of beans with extremely low emittance $(0.25 \mathrm{~mm}-\mathrm{mr})$. Beam 42

During the summer, improvements were made in the HISS cave and experimental area to facilitate equipment changes between runs. All the unused cables left from previous experiments were removed and cables are now being re-installed with labeled, portable patch panels. Included in this project is the installation of a Lecroy 1440 photo-multiplier high voltage supply system which replaces the older 32 channel Lecroy system.

The vacuum leak in the HISS dipole cryostat, which interrupted the HISS program last spring, has been repaired. Fortunately, the failure, a leak in the nitrogen cooling lines surrounding the superconducting coils, could be repaired without removing or dismantling the coil tanks. 
The newly completed $1.5 \mathrm{~m}$ by $2 \mathrm{~m}$ drift chamber was successfully tested with beam this spring. A month following the test a problem developed with wire breakage due to corrosion. Repair work is underway. (H. Wieman)

\section{Beain 44}

Three experimental groups are now associated with this beam line. Their interests include low-energy, kaon and radioactive beam experiments. A large C magnet was installed upstrean of the scattering chamber for use by the radioactive beam group. The magnet is on rails such that it mady be maved out of the beam 1ine. To facilitate future kaon experiments at the beam line, a $C$ magnet has been prepared and tested for use as a beam swinger. The magnet will be installed just upstream of the SiM7 magnet in the septum channe1. The radioactive beam group (Mirror Magnetic Moments) very successfully ran the beam line as a isotope separator. They were able to isolate various fluorine isotopes and measure their half-lives as a precursor to separating and delivering $\mathbf{I j}$ isotopes.

\section{F. At the SUperHILAC}

Accelerator Improvement Project 1986--Uranium Upgrade-II

This AIP project has as its main goal a factor of five increase in very heavy ( $A U, U$ ) ion beam intensity delivered to Bevalac experiments, with a smaller increase for light lons. This fall some of the increase will be available at startup due to improved vacuum in the Abel injector, with the new bunchers expected to be on-line by tive beginning of oecember. The newly developed Metal-Vapor Vacuum Arc (MEVVA) source is expected to be installed early in the spring to complete the project. 
Accelerator Improvement Project 1987--SuperHILAC Drift Tube Quadrupoles

Large drops in the effective resistance and field strength of numerius SuperHILAC quadrupole focusing magnets in the high-energy end of the prestripper have been noticed during the last two years. Located inaccessibly inside drift tubes, these magnets are the key to transmission of beams through the Alvarez tanks, and any decrease in performance results in reduced beam intensity. Over the last two sumner shutdowns we have replaced the worst offenders, but many substandard magnets remain, keeping us from running at the maximum possible intensity.

In the coming year we will replace most of the remaining damaged magnets in Groups $V$ and VI. In addition the Groups I and II magnets will be replaced, but by adfustable hybrid rare-earth permanent magnet quads (REQ'S). These magnets offer the advantages of greater effective field strength, adjustability over a wide range of fields by rotating a ring containing properiy aligned magnetic material, and no power consumption. New prototype magnets of this design are now being tested through an accelerated ten-year 1ife-cycle. The principal advantage of installing these magnets in Groups 1 and II will be the added field gradient. leading to further significant transmission improvements.

The overali intensity gain, including the effect of replacing the falling magnets at the end of the Prestripper, is anticipated to be around a factor of two. (8. Feinberg)

\section{G. The 8evalac Upgrade}

As mentioned in the previous Bevalac Operations Update, a plan is being developed to replace the Bevatron with a modern, strong focusing synchrotron. This new ring will offer significant increases in intensity $(x 100$ to 1000$)$, better spill characteristic and duty factor, and improved 
operational flexibility (pulse-to-pulse ion switching) all at reduced operating costs. The present idea is to fit the largest possible ring inside the Bevatron shielding, while achieving the highest possible energy in a design commensurate with the above-stated goals.

A report was presented to NSAC in March, and was favorably reviewed by a special NSAC Subcomittee on Facility Construction in May. Technical design work is progressing, with the aim of producing a conceptual Design Report in early 1987. A workshop on lattice design, injection, extraction, RF, magnet design and power systems is being planned for October 27-28 at LBL. Interested parties may contact John Staples, Rick Gough or Jose Alonso (425) 486-5831 for more details.

This work was supparted by the U.S. Department of Energy under Contract Number DE-ACO3-76SF00098. Lawrence Berkeley Laboratory is an Equal $1190 \mathrm{~s}$

Opportunity Employer. 


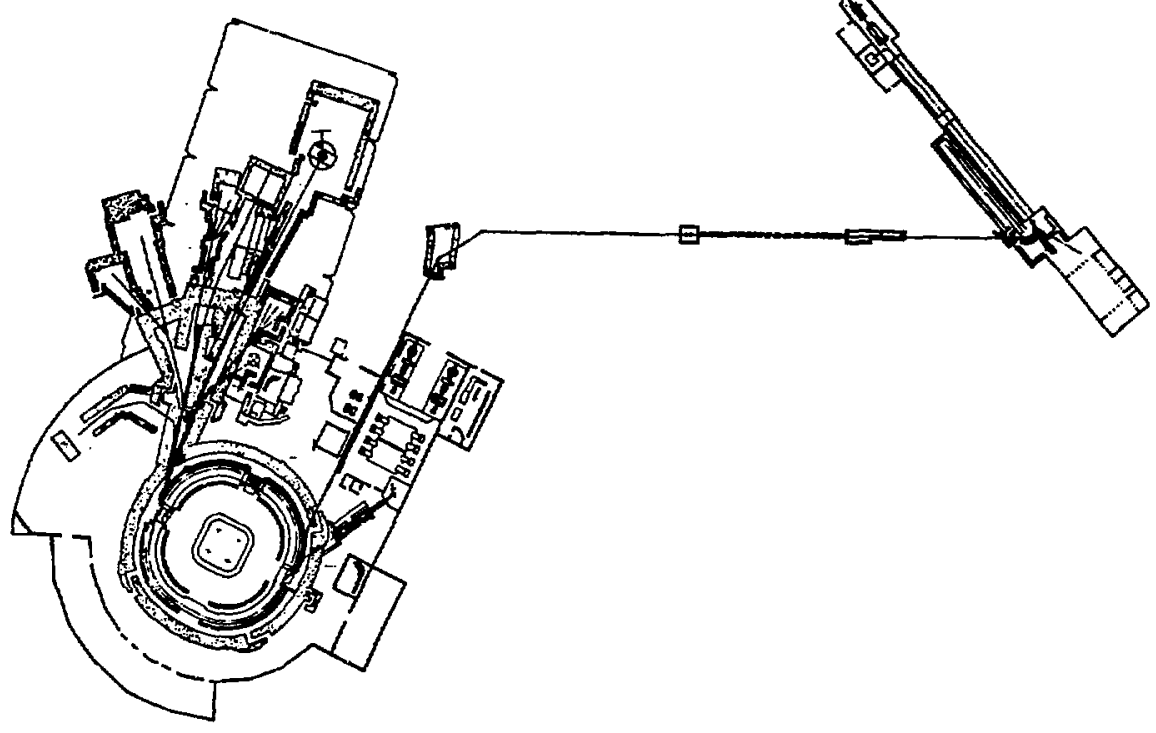

Lawrence Berkeley Laboratory

ARC office

MS 51-208

University of Califarnia

Berkeley, CA 94720

\section{DISCLAIMER}

This report was prepared as an account of work sponsored by an agency of the United States Government. Neither the United States Government nor any agency thereof, nor any of their employecs, makes any warranty, express or implied, or assumes any Iegal liabifity or responsibility for the accuracy, completeness, or usefulness of any information, apparatus, product, or process disclosed, or represents that its use would not infringe privately owned rights. Reference hercin to any specific commercial product, process, or service by trade name, trademark, manufacturer, or otherwise does not necessarily constitu: or imply its endorsement, recommendation, or favoring by the United States Government or any agency thereof. The views and opinions of authors expressed herein do not necessarily state or renect those of the United States Government or any agency ther:of. 